\title{
Resistência ao cisalhamento em vigas de concreto armado sem armadura transversal reforçadas com fibras de aço
}

\author{
Shear strength of steel fiber reinforced concrete beams \\ without transversal reinforcement
}

\section{Paula de Carvalho Palma Vitor Antônio Carlos dos Santos Leandro Mouta Trautwein}

\section{Resumo \\ $\mathbf{N}$}

os últimos anos, pesquisas demonstram o concreto reforçado com fibras de aço como um compósito promissor que pode substituir parte das armaduras convencionais como estribos em vigas, uma vez que as fibras de aço aumentam a resistência ao cisalhamento e tenacidade, o que reduz a possibilidade de ruptura súbita. Neste trabalho foi desenvolvida uma pesquisa experimental para avaliar a influência da adição da fibra de aço na resistência ao cisalhamento e modo de ruptura de vigas de concreto armado sem armadura transversal com a variação da taxa de armadura longitudinal, teor de fibras de aço e resistência do concreto à compressão. Um total de doze vigas foi ensaiado à flexão em quatro pontos. Os resultados experimentais encontrados indicaram que o uso de fibras de aço com ganchos nas extremidades aumentam a resistência ao cisalhamento em vigas e alteram o padrão de fissuração com a formação de pelo menos duas fissuras diagonais e maior número de fissuras de flexão, que proporcionam uma ruptura mais avisada.

Palavras-chave: Vigas. Cisalhamento. Concreto. Fibras de aço.

\section{Abstract}

During the last few years, researchers have demonstrated steel fiber reinforced concrete as a promising composite. This composite can replace part of the conventional reinforcement such as like stirrups in beams once the steel fiber increases the shear strength and stiffness, reducing the possibility of sudden rupture. An experimental study was conducted to evaluate the influence of the addition of steel fiber in the nominal shear strength and failure mode of reinforced concrete beams without transverse reinforcement to the variation of longitudinal reinforcement ratio, steel fiber content and concrete compressive strength. A total of twelve beams were tested using a four point bending test. The experimental results indicated that the use of hooked steel fiber increase the shear strength of beams and alter the pattern of cracks with the formation of at least two diagonal cracks and a greater number of bending cracks providing a warning of the impending beam failure.

Recebido em 25/01/17 Aceito em 18/10/17

Keywords: Beams. Shear. Concrete. Steel fiber. 


\section{Introdução}

O uso de fibras de aço aumenta substancialmente a capacidade de resistência ao esforço cortante de vigas, sendo tais fibras utilizadas como complemento ou como substituição da armadura de cisalhamento convencional (AMERICAN..., 2009). $\mathrm{O}$ aumento na resistência ao cisalhamento proporcionado pelas fibras de aço se deve fundamentalmente à maior resistência à tração residual do concreto reforçado com fibras de aço (CRFA) fissurado. A adição de fibras de aço ao concreto faz com que esse material passe a apresentar um comportamento pseudodúctil, ou seja, continue apresentando uma resistência residual aos esforços mesmo após sua fissuração (FIGUEIREDO, 2011). O reforço das fibras transfere as tensões de tração por meio das fissuras, reduz o espaçamento e largura da fissura diagonal crítica, o que aumenta o mecanismo de engrenamento dos agregados (DINH; PARRAMONTESINOS; WIGHT, 2010).

Pesquisas relatam aumento da resistência ao esforço cortante de até $258 \%$, quando são adicionadas fibras ao concreto de vigas de resistência normal (SLATER; MONI; ALAM, 2012). No entanto, o ganho de resistência ao esforço cortante pode variar dependendo das características do ensaio, das propriedades das vigas, propriedades das fibras, teor de fibras adicionado ao concreto $\left(V_{f}\right)$, propriedades da matriz e características do ensaio.

Numerosos estudos (KWAK et al., 2002; DINH; PARRA-MONTESINOS; WIGHT, 2010; YAKOUB, 2011; AOUDE et al., 2012; KANG et al., 2012; SLATER; MONI; ALAM, 2012, SINGH; JAIN, 2014; SAHOO; SHARMA, 2014, dentre outros) analisaram o comportamento ao cisalhamento de vigas de CRFA. Nesses estudos, o efeito de vários parâmetros como a relação entre o vão de cisalhamento $a$ e a altura útil da viga $d(a / d)$, taxa de armadura longitudinal de tração $(\rho), V_{f}$ e resistência à compressão do concreto $\left(f_{c}\right)$ na resistência ao cisalhamento e modo de ruptura das vigas foram considerados.

Dinh, Parra-Montesinos e Wight (2010) concluíram que o uso de fibras com gancho nas extremidades com teor de fibras maior ou igual a $0,75 \%\left(60 \mathrm{~kg} / \mathrm{m}^{3}\right.$ de concreto) aumenta a resistência ao cisalhamento de vigas sem armadura transversal, podendo essas ser utilizadas como armadura mínima de cisalhamento. Yakoub (2011) verificou elevação na tensão de ruptura por cisalhamento com aumento do teor de fibras e taxa de armadura longitudinal de tração em estudo analítico de 218 ensaios de ruptura por cortante em vigas de CRFA sem estribos. Singh e Jain (2014) verificaram aumento na resistência ao cisalhamento com o aumento do teor de fibras e do fator de forma das fibras (relação entre 0 comprimento da fibra, $l_{f}$, e seu diâmetro, $d_{f}, l_{f} / d_{f}$ ) durante a avaliação da resistência ao cisalhamento de 43 vigas de concreto armado de resistência normal e de alta resistência contendo fibras de aço, como proposta de armadura mínima de cisalhamento.

Nas pesquisas de Dinh, Parra-Montesinos e Wight (2010) e Singh e Jain (2014), o padrão de fissuração das vigas de concreto armado e das vigas de CRFA foi distintamente diferente. Enquanto as vigas de concreto armado sem armadura transversal no vão testado apresentaram uma fissura diagonal única seguida por uma ruptura frágil, as vigas de CRFA apresentaram pelo menos duas fissuras e 0 alargamento de pelo uma delas antes da ruptura proporcionou algum aviso sobre a ruptura eminente. Segundo Sahoo e Sharma (2014), a adição de no mínimo $1,0 \%$ de fibras $\left(78,5 \mathrm{~kg} / \mathrm{m}^{3}\right.$ de concreto) muda o modo de ruptura das vigas sem armadura transversal de cortante (frágil) para flexão (dúctil). A elevação do teor de fibras é acompanhada por aumento do mapa de fissuração e redução do espaçamento entre as fissuras de flexão e de cisalhamento (SAHOO; SHARMA, 2014; KWAK et al., 2002)

Segundo Sahoo e Sharma (2014), o teor de fibras tem uma influência mais importante na resistência ao cisalhamento de vigas de CRFA quando comparada com a taxa de armadura longitudinal. O principal efeito da taxa de armadura seria sobre a ductilidade das vigas, em que a ocorrência do escoamento das armaduras de tração é principalmente associada como teor de fibras (DINH; PARRA-MONTESINOS; WIGHT, 2010).

Considerando os aspectos normativos, apesar de as fibras de aço serem reconhecidas como material estrutural pelas diretrizes ACI 318 Building Code Requirements for Structural Concrete (AMERICAN..., 2014) e FIB Model Code (FÉDÉRATION..., 2010), ainda há uma carência de normas com orientações para cálculo da resistência ao cisalhamento de elementos de CRFA submetidos à flexão. De acordo com Sahoo e Sharma (2014), pesquisas ainda são necessárias para entender o comportamento de vigas de CRFA submetidas à flexão e assim ser possível validar as equações propostas pelos pesquisadores e desenvolver ferramentas numéricas mais precisas. Diante disso, investigações experimentais ainda são necessárias para identificar como alguns parâmetros afetam a resistência ao cisalhamento de vigas de CRFA.

Nesta pesquisa, os principais parâmetros influenciadores da resistência ao cisalhamento em 
vigas de CRFA foram: a resistência do concreto à compressão, a taxa de armadura longitudinal de tração e o teor de fibras de aço.

Historicamente o reforço do concreto é realizado com barras de aço contínuas para resistir às tensões de tração e cisalhamento. Entretanto, a execução das armaduras pode demandar uma grande parcela de tempo do processo construtivo, o que contribui para o aumento do custo. Pesquisas realizadas nos últimos anos (KWAK et al., 2002; DINH; PARRAMONTESINOS; WIGHT, 2010; YAKOUB, 2011; AOUDE et al., 2012; KANG et al., 2012; SLATER; MONI; ALAM, 2012; SINGH; JAIN, 2014; SAHOO; SHARMA, 2014, dentre outros) mostram o CRFA como uma opção viável para aumento da resistência ao cisalhamento, que reduz a possibilidade de ruptura súbita em vigas sem armadura transversal. Apesar de esse assunto já ser adotado em diretrizes internacionais como ACI 318 (AMERICAN..., 2014) e FIB ModelCode (FÉDÉRATION..., 2010), há uma dificuldade de prever com precisão o aumento da resistência ao cisalhamento em vigas de CRFA devido ao já complexo mecanismo de transferência da força cortante nesses elementos submetidos à flexão.

Pesquisas com CRFA ainda são necessárias para investigar o comportamento de vigas de CRFA submetidas à flexão para as várias combinações de relação $a / d$, teor de fibras, classe de resistência do concreto e taxa de armadura longitudinal para prever com precisão a resistência ao cisalhamento e assim criar e validar procedimentos normativos. Para tanto, os objetivos deste estudo foram avaliar a influência da adição da fibra de aço na resistência ao cisalhamento e modo de ruptura em vigas de concreto armado com a variação da taxa de armadura longitudinal, teor de fibras de aço e resistência do concreto à compressão.

\section{Materiais e métodos}

Um total de 12 vigas de concreto armado biapoiadas (vão teórico $2.000 \mathrm{~mm}$ ), sem armadura transversal na região dos esforços cortantes, foram ensaiadas à flexão em quatro pontos (Figura 1) até a ruptura para avaliar a influência do teor de fibras, taxa de armadura longitudinal de tração e resistência do concreto à compressão no modo de ruptura e resistência da viga ao cisalhamento. O vão de cisalhamento $a$ foi de $700 \mathrm{~mm}$.

O programa experimental consistiu em duas séries de vigas. A série S20 foi composta de 6 vigas moldadas com concreto classe de resistência à compressão de $20 \mathrm{MPa}$ e série S40, composta de 6 vigas moldadas com concreto classe de resistência à compressão de $40 \mathrm{MPa}$. As vigas de ambas as séries apresentavam mesmas dimensões: $2.400 \mathrm{~mm}$ de comprimento, $150 \mathrm{~mm}$ de largura e $300 \mathrm{~mm}$ de altura.

Tanto para a série S20 e S40 foram utilizados três teores de fibras, $0,0 \%, 0,64 \%$ e $0,77 \%\left(50 \mathrm{~kg} / \mathrm{m}^{3}\right.$ e $60 \mathrm{~kg} / \mathrm{m}^{3}$ ) e duas taxas de armadura longitudinal, $1,32 \%$ (4Ø 12,5) e $1,5 \%$ (3 Ø 16,0). O teor de fibra foi calculado considerando que $1 \%$ de fibra de aço por volume de concreto tem um peso de $78,5 \mathrm{~kg} / \mathrm{m}^{3}$. A taxa de armadura foi calculada utilizando a Equação 1, sendo a área de aço $\left(\mathrm{A}_{\mathrm{s}}\right)$ de $4,91 \mathrm{~cm}^{2}$ para 4 Ø 12,5 e 6,03 $\mathrm{cm}^{2}$ para 3 Ø 16,0 e; a largura da seção $b_{\mathrm{w}}$ de $15 \mathrm{~cm}$.

$\rho=\frac{A_{s}}{d \times b_{w}}$

Eq. 1

Onde:

$\rho$ : taxa de armadura, em \%;

$A_{s}$ : área de armadura, em $\mathrm{cm}^{2}$;

$d$ : altura útil, em $\mathrm{cm}$; e

$b_{w}$ : largura da viga, em cm.

A Tabela 1 lista as propriedades das vigas ensaiadas. $\mathrm{O}$ ensaio de abatimento de tronco de cone foi realizado conforme NBR NM 67 (1998).

A denominação adotada para as vigas foi baseada na série S20 ou S40, taxa de armadura longitudinal A (1,32 \%) ou B (1,55\%) e teor de fibras de aço adicionado à matriz de concreto $(0 \%, 0,64 \%$ ou 0,77\%).

Na Figura 2 são vistos a geometria e o detalhamento das armaduras tipo A e tipo B das vigas.

\section{Figura 1 - Esquema de ensaio}

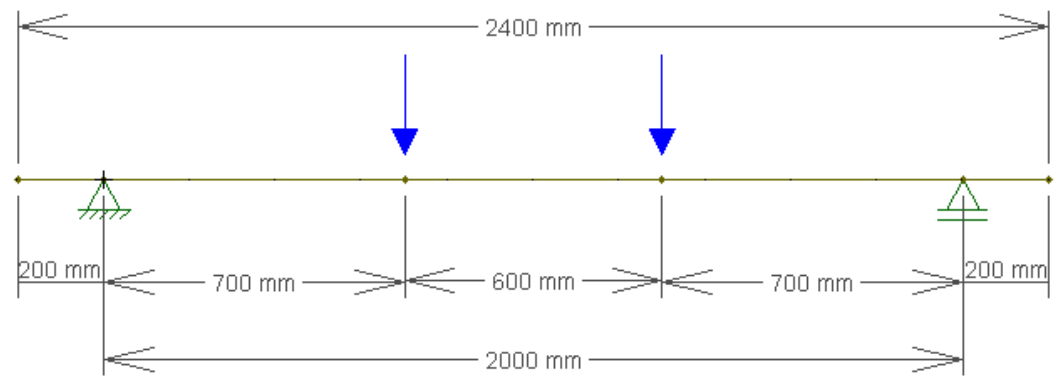


Tabela 1 - Características das vigas

Nota: Legenda:

\begin{tabular}{|c|c|c|c|c|c|c|c|c|}
\hline Vigas & $\begin{array}{c}\mathbf{d} \\
(\mathbf{m m}) \\
\end{array}$ & $a / d$ & $\begin{array}{c}\rho \\
(\%) \\
\end{array}$ & $f_{y}^{1}(\mathrm{MPa})$ & $\begin{array}{c}V_{f} \\
(\%) \\
\end{array}$ & $\begin{array}{c}f_{c t^{2}} \\
(\mathrm{MPa}) \\
\end{array}$ & $\begin{array}{c}f_{c} \\
(\mathbf{M P a}) \\
\end{array}$ & \begin{tabular}{|c|}
$\begin{array}{c}\text { Abatimento } \\
(\mathrm{mm})\end{array}$ \\
\end{tabular} \\
\hline S20A-0 & 247,5 & 2,83 & 1,32 & 581,12 & 0,00 & 2,43 & 23,93 & 110 \\
\hline S20A-0,64 & 247,5 & 2,83 & 1,32 & 581,12 & 0,64 & 3,16 & 22,32 & 75 \\
\hline S20A-0,77 & 247,5 & 2,83 & 1,32 & 581,12 & 0,77 & 3,33 & 24,16 & 100 \\
\hline S20B-0 & 262,0 & 2,67 & 1,55 & 606,65 & 0,00 & 2,98 & 28,54 & 120 \\
\hline S20B-0,64 & 262,0 & 2,67 & 1,55 & 606,65 & 0,64 & 2,69 & 26,92 & 90 \\
\hline S20B-0,77 & 262,0 & 2,67 & 1,55 & 606,65 & 0,77 & 3,08 & 23,76 & 110 \\
\hline S40A-0 & 262,0 & 2,83 & 1,32 & 581,12 & 0,00 & 3,41 & 35,67 & 140 \\
\hline S40A-0,64 & 247,5 & 2,83 & 1,32 & 581,12 & 0,64 & 5,42 & 35,70 & 55 \\
\hline S40A-0,77 & 247,5 & 2,83 & 1,32 & 581,12 & 0,77 & 4,99 & 42,43 & 100 \\
\hline S40B-0 & 262,0 & 2,67 & 1,55 & 606,65 & 0,00 & 3,27 & 36,29 & 130 \\
\hline S40B-0,64 & 262,0 & 2,67 & 1,55 & 595,98 & 0,64 & 4,40 & 39,38 & 55 \\
\hline S40B-0,77 & 262,0 & 2,67 & 1,55 & 606,65 & 0,77 & 5,46 & 37,05 & 120 \\
\hline
\end{tabular}

${ }^{1} f_{y}$ (resistência ao escoamento do aço); e

${ }^{2} \mathrm{f}_{\mathrm{ct}}$ (resistência à tração por compressão diametral).

Figura 2 - Armaduras

Viga $15 \times 30$ - Tipo A

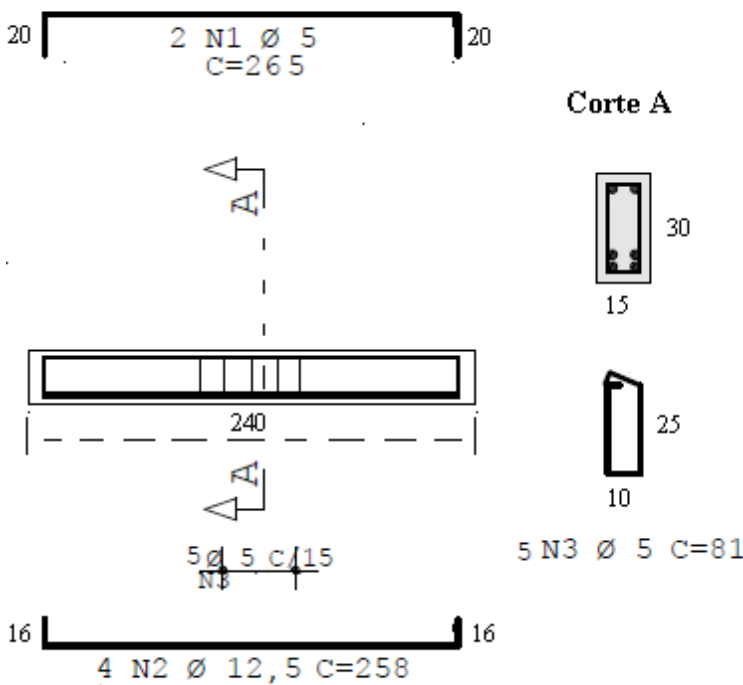

Dimensões em cm

Diâmetro do aço em mm

Para as armaduras do tipo A ( $\varnothing 12,5 \mathrm{~mm})$, a altura útil foi de $247,5 \mathrm{~mm}$ e 262,0 $\mathrm{mm}$ para as armaduras tipo B ( $\varnothing 16 \mathrm{~mm})$. O cobrimento das armaduras foi de $25 \mathrm{~mm}$, exceto na região normal aos ganchos, em que o cobrimento foi de $70 \mathrm{~mm}$.

As ancoragens das armaduras longitudinais de tração nas extremidades das vigas foram realizadas por meio do cálculo do comprimento reto das armaduras e do gancho de ancoragem segundo a norma brasileira NBR 6118 (ABNT, 2014) correspondente a $160 \mathrm{~mm}$ para as barras de $12,5 \mathrm{~mm}$ e $200 \mathrm{~mm}$ para as barras de $16,0 \mathrm{~mm}$. Uma vez que o momento negativo nas vigas era nulo, foram
Viga $15 \times 30$ - Tipo B

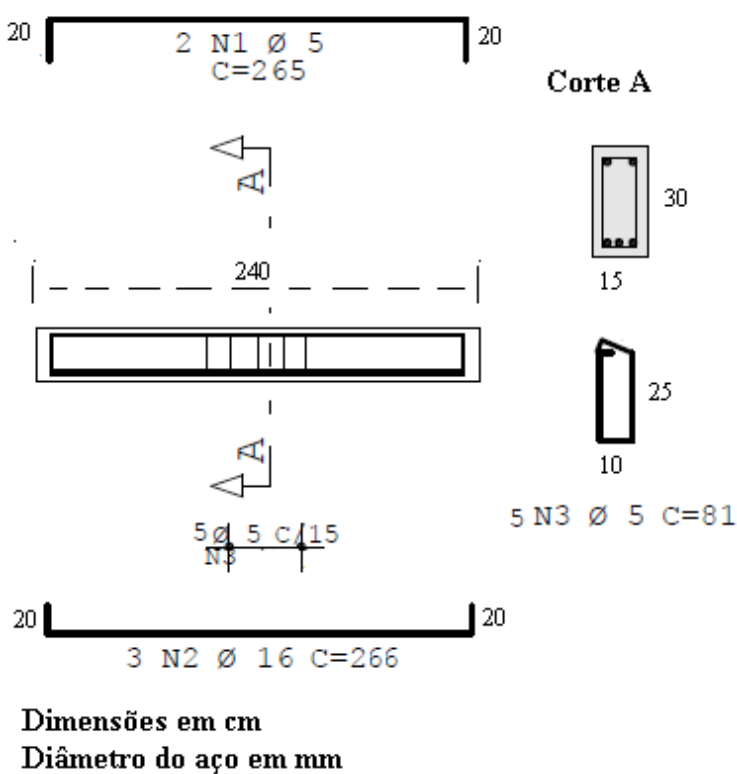

utilizadas 2 barras de aço CA 60 de $5 \mathrm{~mm}$ como armadura longitudinal superior, para efeitos construtivos.

\section{Instrumentação das vigas}

As deformações específicas nas armaduras e no concreto foram mensuradas com a utilização de extensômetros elétricos. Os extensômetros foram colados na armadura longitudinal de tração e no concreto com a utilização de adesivo à base de cianocrilato, isolados e impermeabilizados com fita isolante plástica. A codificação adotada para a identificação dos pontos instrumentados obedeceu 
ao seguinte critério: foi designada a letra L para extensômetros colocados na armadura longitudinal de tração e a letra $C$ para os extensômetros colocados na região de compressão na face superior da viga. Para cada posição foram colocados dois extensômetros, um em cada barra da armadura longitudinal existente na primeira camada.

Na Figura 3 são apresentados os detalhes das posições dos extensômetros nas armaduras e no concreto, com as suas respectivas posições e nomenclaturas. Nesta figura também são vistos o posicionamento de três transformadores diferenciais variáveis lineares (LVDT), um no meio do vão para medida do deslocamento vertical e os outros dois para monitorar qualquer deslocamento no apoio.

\section{Materiais e moldagem do concreto}

Na Tabela 2 são vistos o consumo dos materiais para $1 \mathrm{~m}^{3}$ de concreto.

A relação água/cimento (a/c) foi 0,70 para a série S20 e 0,43 para a série S40. Foram utilizados o cimento CP III $40 \mathrm{RS}$, agregado miúdo de areia lavada de rio e os agregados graúdos de pedra britada de rocha basáltica. As fibras de aço foram do tipo com gancho na extremidade (Figura 4), comprimento de $60 \mathrm{~mm}$, diâmetro de $0,90 \mathrm{~mm}$, fator de forma de 65, resistência à tração de $1.160 \mathrm{MPa}$ e módulo de elasticidade de 210 GPa.

Em todos os traços foi utilizado aditivo superplastificante para melhora da trabalhabilidade.

\section{Figura 3 - Posicionamento dos extensômetros}

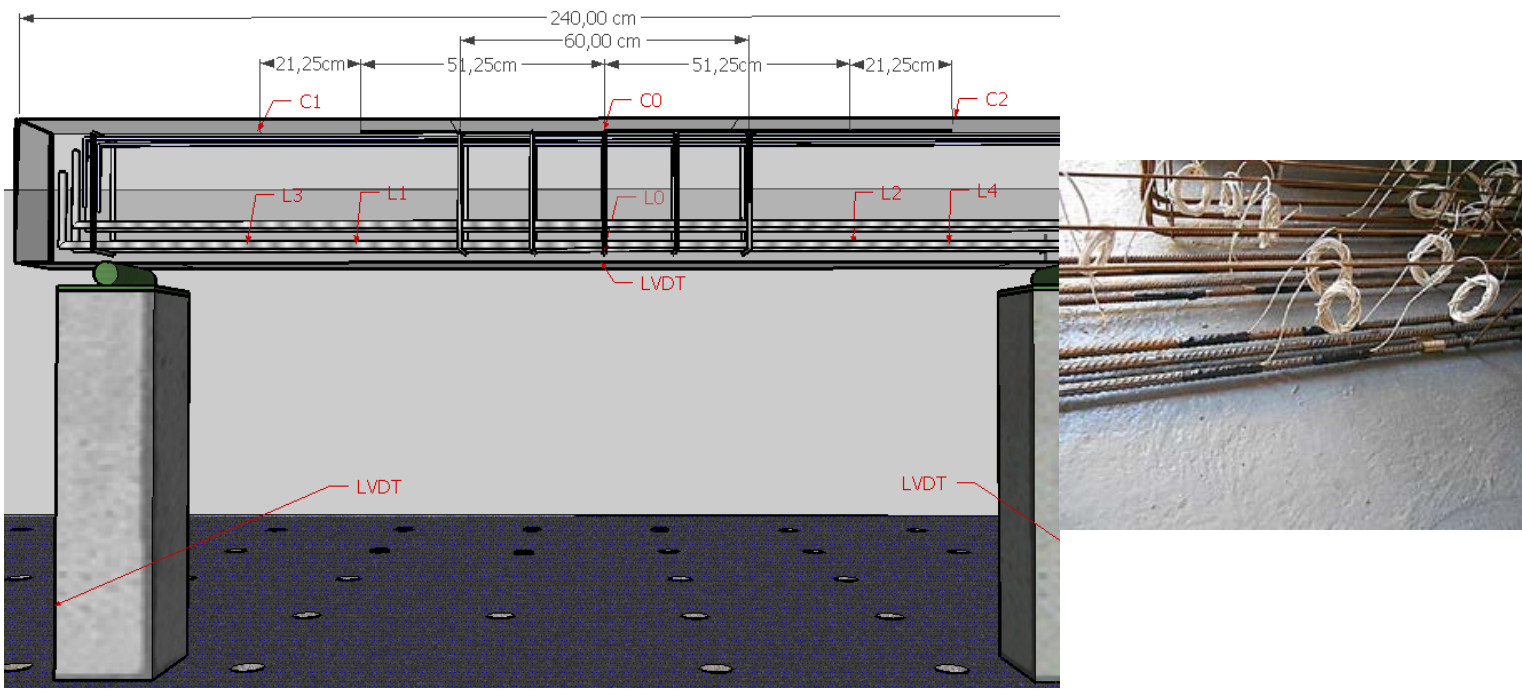

Tabela 2 - Consumo de materiais

\begin{tabular}{|c|c|c|c|c|c|c|}
\hline \multirow{3}{*}{ Componentes } & \multirow{2}{*}{\multicolumn{3}{|c|}{$\begin{array}{c}\text { Série S20 } \\
\text { Teor de fibras }\end{array}$}} & \multirow{2}{*}{\multicolumn{3}{|c|}{$\begin{array}{c}\text { Série S40 } \\
\text { Teor de fibras }\end{array}$}} \\
\hline & & & & & & \\
\hline & Sem fibras & $50 \mathrm{~kg} / \mathrm{m}^{3}$ & $60 \mathrm{~kg} / \mathrm{m}^{3}$ & $\begin{array}{c}\text { Sem } \\
\text { fibras }\end{array}$ & $50 \mathrm{~kg} / \mathrm{m}^{3}$ & $60 \mathrm{~kg} / \mathrm{m}^{3}$ \\
\hline Cimento $\left(\mathrm{kg} / \mathrm{m}^{3}\right)$ & 300,30 & 300,30 & 300,30 & 447,00 & 447,00 & 447,00 \\
\hline Areia fina $\left(\mathrm{kg} / \mathrm{m}^{3}\right)$ & 276,28 & 276,28 & 276,28 & 250,32 & 250,32 & 250,32 \\
\hline Areia média $\left(\mathrm{kg} / \mathrm{m}^{3}\right)$ & 516,52 & 516,52 & 516,52 & 464,88 & 464,88 & 464,88 \\
\hline $\begin{array}{l}\text { Agregado graúdo Dmax 12,5 } \\
\mathrm{mm}\left(\mathrm{kg} / \mathrm{m}^{3}\right)\end{array}$ & 252,25 & 252,25 & 252,25 & 268,20 & 268,20 & 268,20 \\
\hline $\begin{array}{l}\text { Agregado graúdo Dmax } 19 \text { mm } \\
\left(\mathrm{kg} / \mathrm{m}^{3}\right)\end{array}$ & 757,76 & 757,76 & 757,76 & 804,60 & 804,60 & 804,60 \\
\hline Água $\left(1 / \mathrm{m}^{3}\right)$ & 198,20 & 198,20 & 198,20 & 179,80 & 179,80 & 179,80 \\
\hline Aditivo $\left(\mathrm{l} / \mathrm{m}^{3}\right)$ & 0,29 & 0,57 & 1,29 & 1,28 & $2,13^{1}$ & 2,34 \\
\hline Teor de ar (\%) & 2,00 & 2,00 & 2,00 & 2,00 & 2,00 & 2,00 \\
\hline Teor de fibra $\left(\mathrm{kg} / \mathrm{m}^{3}\right)$ & NA & 50 & 60 & NA & 50 & 60 \\
\hline Teor de fibras em volume (\%) & NA & 0,6 & 0,7 & NA & 0,6 & 0,76 \\
\hline
\end{tabular}


Figura 4 - Fibras de aço
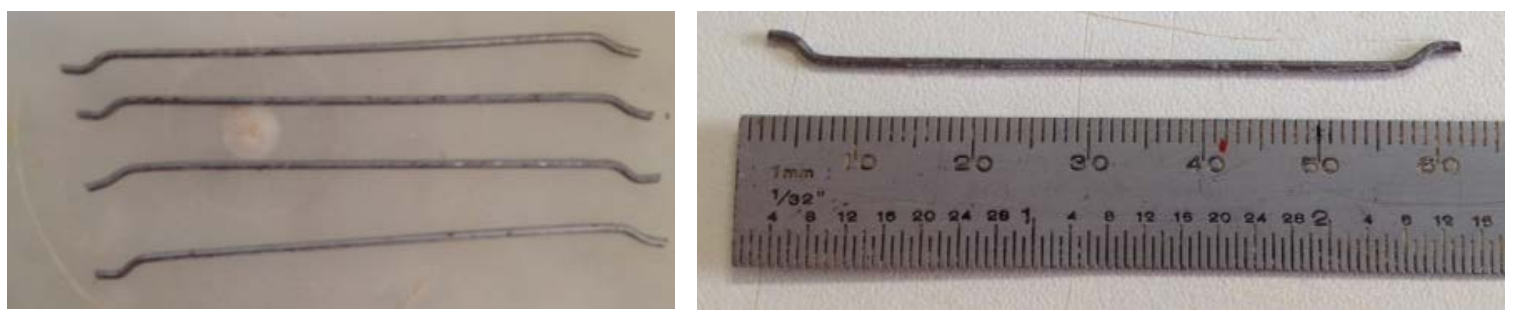

Figura 5 - Lançamento, adensamento e cura das vigas
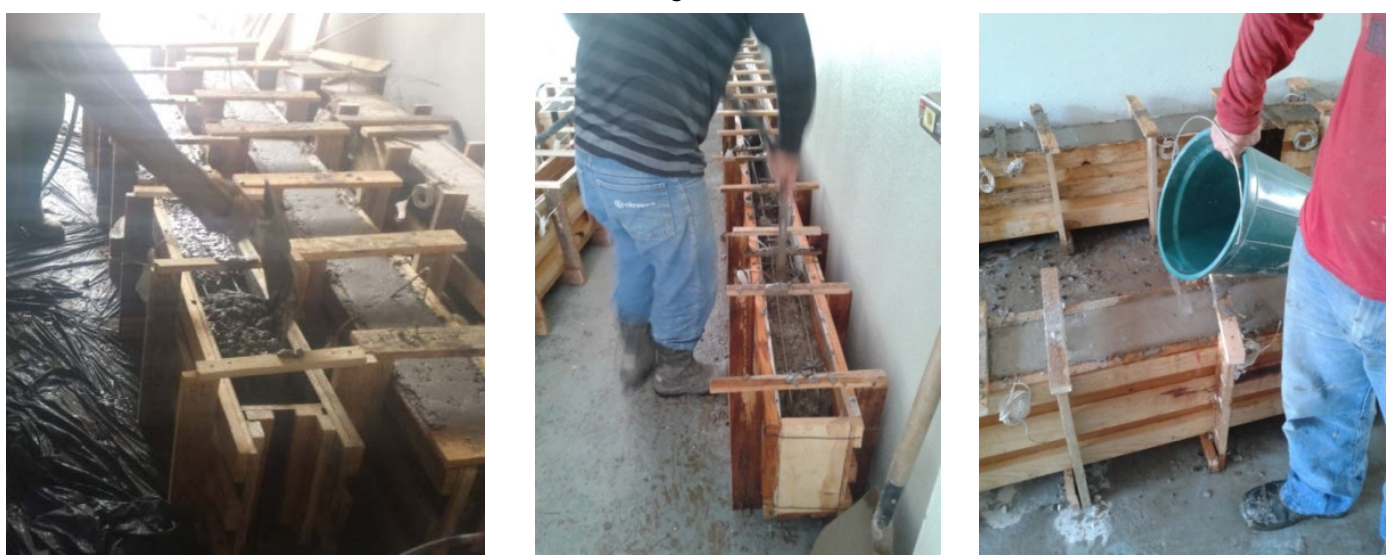

O concreto foi produzido com o uso de betoneira com capacidade de 400 litros, localizada no Laboratório de Estruturas e Construção Civil da Universidade Federal de Uberlândia. Para cada viga foram moldados 6 corpos de prova cilíndricos (100 mm x 200 mm), 3 para a verificação da resistência à compressão pela norma NBR 5739 (ABNT, 2007) e 3 para resistência à tração por compressão diametral conforme NBR 7222 (ABNT, 2011). Os corpos de prova ficaram 24 horas em câmara úmida, posteriormente foram desinformados e mantidos em cura submersa até a data de realização dos ensaios. Esses ensaios foram realizados na mesma data de realização dos ensaios das vigas.

O adensamento foi realizado com vibrador de imersão de agulha de 25 mm de diâmetro (Figura 5). Durante sete dias foi realizada a aspersão de água nas vigas para cura. As vigas foram mantidas nas fôrmas até as datas de execução dos ensaios.

\section{Execução dos ensaios}

As 12 vigas foram ensaiadas em dias distintos. No entanto, para minimizar a influência da resistência do concreto nos resultados, os ensaios foram realizados com mais de 120 dias de cura do concreto para que o ganho de resistência com a idade do concreto fosse de menor amplitude. Para aplicação das cargas foi utilizado o pórtico metálico montado sobre a laje de reação do Laboratório de Estruturas da Universidade Federal de Uberlândia.
Durante o ensaio, as vigas ficaram apoiadas em dois roletes. Cada um dos roletes foi apoiado em um bloco de concreto. O carregamento da viga foi aplicado por atuador hidráulico alimentado por uma bomba manual e transferido a dois pontos simétricos da viga afastados de $600 \mathrm{~mm}$ de cada um dos apoios, por meio de uma viga constituída por perfil metálico "I" (Figura 6).

Para a medição do carregamento, foi utilizada uma célula de carga de $500 \mathrm{kN}$. A viga de perfil "I" ficou interposta entre a célula de carga e a viga de concreto. Essa viga metálica transferiu a carga do atuador hidráulico para duas placas de aço de $5 \mathrm{~cm}$ de largura, as quais foram apoiadas e niveladas com argamassa sobre a viga de concreto.

A força foi aplicada com incrementos de $15 \mathrm{kN}$ e mantida em tempo médio aproximado de 30 segundos. Para melhor visualização das fissuras, as vigas foram previamente pintadas com pintura de cal e divididas em quadrantes.

O controle das cargas aplicadas durante os ensaios foi efetuado pelo monitoramento dos sinais da célula de carga ligada a um sistema aquisitor de dados. Os dados da célula de carga, as deformações das armaduras e do concreto e o deslocamento no meio do vão e nos apoios foram armazenados pelo equipamento aquisitor de dados, para uma frequência de $5 \mathrm{~Hz}$.

Os ensaios de resistência à compressão e resistência à tração por compressão diametral foram realizados 
na mesma data de ensaio da respectiva viga utilizando a prensa eletromecânica EMIC ${ }^{\circledR}$ modelo DL-60000, servo-controlada (Figura 7). A prensa possui capacidade de carga de $600 \mathrm{kN}$.

\section{Resultados e discussão}

Os resultados de força última, força cortante última, resistência ao cisalhamento última, resistência ao cisalhamento padronizada pela resistência à compressão $v_{u} / \sqrt{f_{c}}$ e modo de ruptura podem ser visualizados na Tabela 3 .

\section{Propriedades do concreto endurecido}

O efeito da adição de fibras na resistência à compressão média e resistência à tração por compressão diametral média do concreto podem ser vistos na Figura 8.

O acréscimo de fibras de aço ao concreto exerceu influência pouco significativa (probabilidade de significância superior a 0,05 na análise de variância com nível de significância de 5\%) ou mesmo uma redução na resistência à compressão conforme já observado por Bentur e Mindess (2007) e Mehta e Monteiro (2014). Esses autores relatam que o acréscimo de fibras de aço no concreto em teores inferiores a $2 \%$ por volume exerce influência desprezível na resistência à compressão. A redução da resistência à compressão pode ser creditada à má compactação do concreto ou ao aumento do teor de ar incorporado, o que provocaria uma redução da resistência superior ao aumento produzido pelas fibras (OLIVEIRA JUNIOR, 2012).

Analisando o efeito das fibras na resistência à tração por compressão diametral, foram observados na série S20 aumentos na resistência à tração média de até $18,08 \%$ (teor de fibras de $0,77 \%$ ) quando comparados ao concreto sem fibras. Na série S40, a resistência à tração do concreto produzido com teor de fibras de $0,64 \%$ e $0,77 \%$ foram $47,45 \%$ e $56,76 \%$ superiores ao concreto sem fibras, respectivamente.

\section{Figura 6 - Configuração do ensaio}

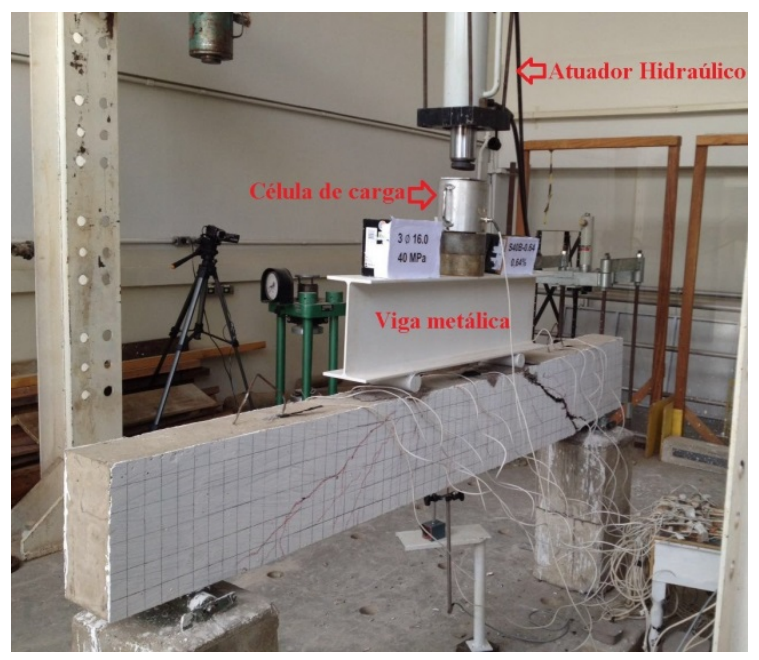

Figura 7 - Ensaio dos corpos de prova cilíndricos
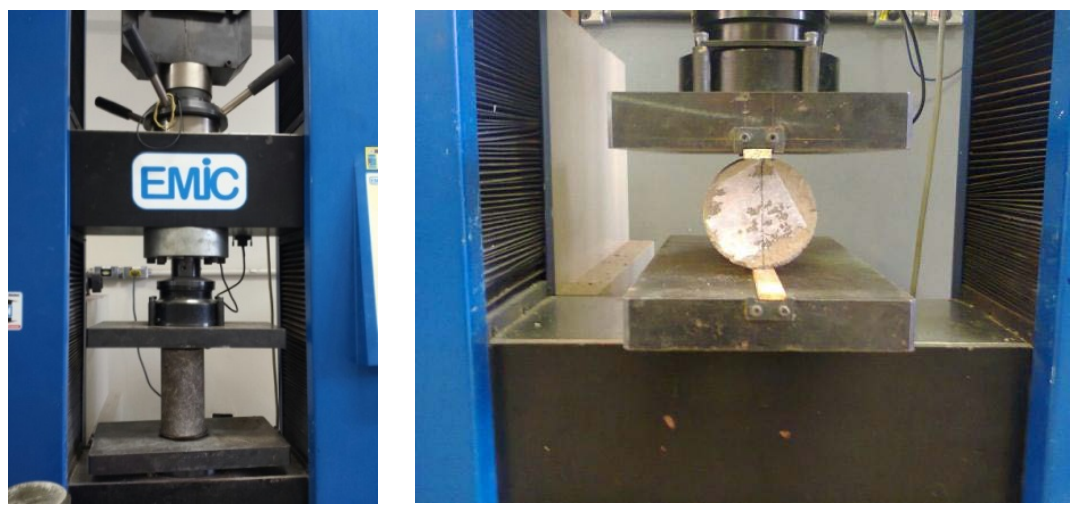
Tabela 3 - Resultados experimentais

\begin{tabular}{l|c|c|c|c|c}
\hline \multicolumn{1}{c|}{ Vigas } & $\mathbf{P}_{\mathbf{u}}{ }^{\mathbf{1}}(\mathbf{k N})$ & $\mathbf{V}_{\mathbf{u}}{ }^{\mathbf{2}}(\mathbf{k N})$ & $\left.\mathbf{v}_{\mathbf{u}}{ }^{3} \mathbf{M P a}\right)$ & $\boldsymbol{v}_{\boldsymbol{u}} / \sqrt{\boldsymbol{f}_{\boldsymbol{c}}}$ & Modo de ruptura \\
\hline S20A-0 & 111 & 55,5 & 1,495 & 0,306 & Cortante \\
S20A-0,64 & 145 & 72,5 & 1,953 & 0,413 & Cortante \\
S20A-0,77 & 213 & 106,5 & 2,869 & 0,584 & Cortante \\
S20B-0 & 113 & 56,5 & 1,438 & 0,269 & Cortante \\
S20B-0,64 & 162 & 81,0 & 2,061 & 0,397 & Cortante \\
S20B-0,77 & 185 & 92,5 & 2,354 & 0,483 & Cortante \\
S40A-0 & 120 & 60,0 & 1,616 & 0,271 & Cortante \\
S40A-0,64 & 210 & 104,5 & 2,815 & 0,470 & Flexo-cortante \\
S40A-0,77 & 202 & 101,0 & 2,720 & 0,420 & Flexo-cortante \\
S40B-0 & 137 & 68,5 & 1,743 & 0,289 & Cortante \\
S40B-0,64 & 246 & 123,0 & 3,130 & 0,499 & Flexo-cortante \\
S40B-0,77 & 230 & 115,0 & 2,926 & 0,481 & Cortante \\
\hline
\end{tabular}

Nota: Legenda:

${ }^{1} \mathrm{Pu}$ (Força última):

${ }^{2} \mathrm{Vu}$ (Cortante última); e

${ }^{3} \mathrm{vu}$ (Tensão de cisalhamento última).

Figura 8 - Efeito da adição de fibras de aço na resistência à compressão e tração do concreto

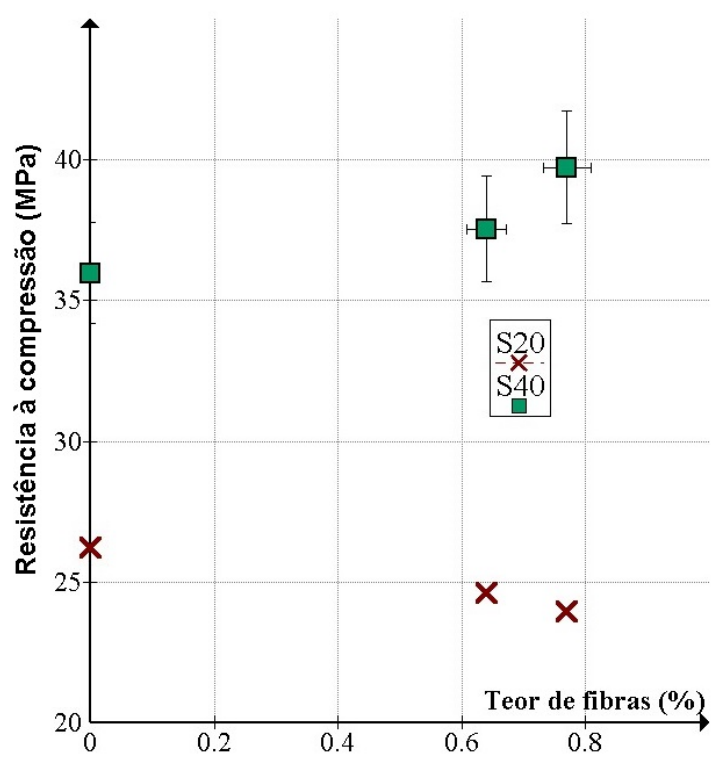

(a)

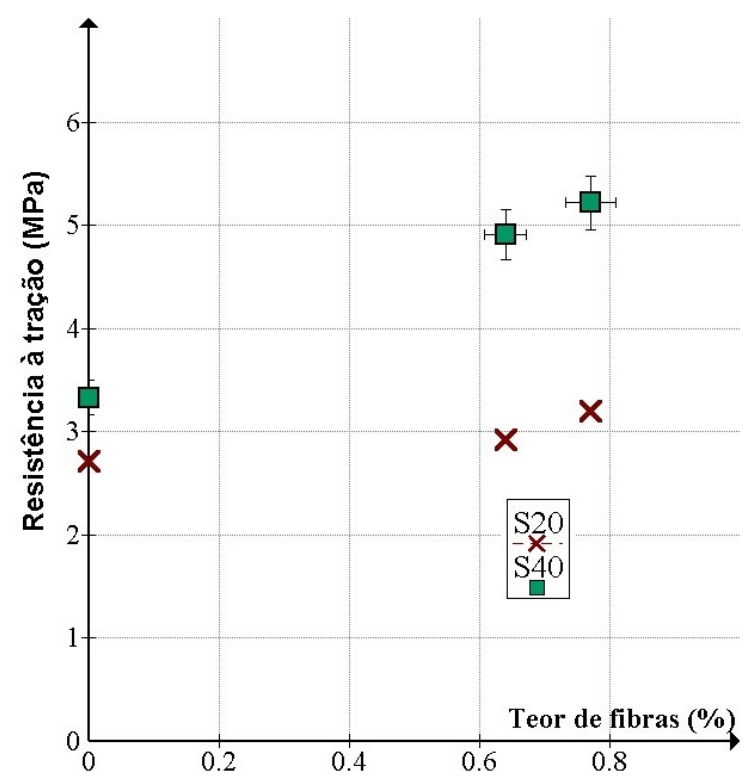

(b)

Para verificar se houve influência significativa da adição de fibras na resistência à tração do concreto por compressão diametral foram realizadas análises de variância com nível de significância de 5\% para a série S20 e S40. Conforme é visto na Figura 9, os resultados sugerem influência significativa da adição de fibras na resistência à tração média por compressão diametral somente na série S40, em que o valor de "valor-p" foi de 0,0039 .

\section{Resposta carga-deslocamento}

As curvas momento fletor $\times$ deslocamento no meio do vão quando mantida constante a resistência à compressão são mostradas na Figura 10.

Pode ser observado que todas as vigas apresentaram comportamento linear da carga inicial até o aparecimento da primeira fissura diagonal. As vigas sem adição de fibras (S20A-0, S20B-0, S40A-0 e S40B-0) apresentaram uma perda repentina da capacidade de suportar a carga imediatamente após o momento último $\left(\mathrm{M}_{\mathrm{u}}\right)$ ser alcançado devido ao 
rápido aumento da fissura diagonal. A comparação do deslocamento máximo no meio do vão no $\mathrm{M}_{\mathrm{u}}$ revela que houve melhora na ductilidade com a inclusão de fibras. Nas vigas de CRFA o desenvolvimento das fissuras de cisalhamento não foi acompanhado por uma queda súbita da capacidade de suportar o carregamento.

Nas curvas referentes às vigas S40A-0,64 $\left(f_{c} 40\right.$ $\mathrm{MPa}, \rho 1,32 \%$ e $\left.V_{f} 0,64 \%\right)$, S40A-0,77 ( $f_{c} 40 \mathrm{MPa}$, $\rho 1,32 \%$ e $\left.V_{f} 0,77 \%\right)$, ) e S40B-0,64 ( $f_{c} 40 \mathrm{MPa}, \rho$ $1,55 \%$ e $\left.V_{f} 0,64 \%\right)$ são vistos patamares de escoamento bem definidos caracterizando escoamento da armadura longitudinal de tração prévio a ruptura. Dinh, Parra-Montesinos e Wight (2010) encontraram resultado semelhante em vigas sem estribos, com $V_{f}$ de $1 \%$ e $\rho$ de $2,0 \%$ e $2,7 \%$. As vigas com menores $\rho(2 \%)$ apresentaram um platô bem definido indicando escoamento da armadura longitudinal anterior à ruptura por cisalhamento. Porém, segundo os autores, o grau de escoamento frequentemente varia, mesmo em um par de vigas semelhante.
Com o aumento do teor de fibras, tanto o momento último $\left(\mathrm{M}_{\mathrm{u}}\right)$ como o deslocamento último aumentaram tanto para a série S20, como para a série S40. O deslocamento último foi definido como o deslocamento na qual a força resistida pela viga caiu significativamente.

\section{Ductilidade}

Para todas as vigas com fibras foi calculado o índice de ductilidade $\mu_{d}$ utilizando a Equação 2. Onde $\delta_{u}$ é o deslocamento vertical na ruptura e $\delta_{y}$ o deslocamento vertical correspondente ao escoamento da armadura. $\delta_{y}$ foi obtido por meio do ponto de concordância gerado pela interseção das retas tangentes aos estágios pós-fissuração e pósescoamento no diagrama força $\mathrm{x}$ deslocamento.

$\mu_{d}=\frac{\delta_{u}}{\delta_{y}}$

Eq. 2

Na Tabela 4 são vistos os resultados de $\mu_{d}$.

Figura 9 - Análise de variância resistência à tração por compressão diametral Série S20 (a) e Série S40 (b)

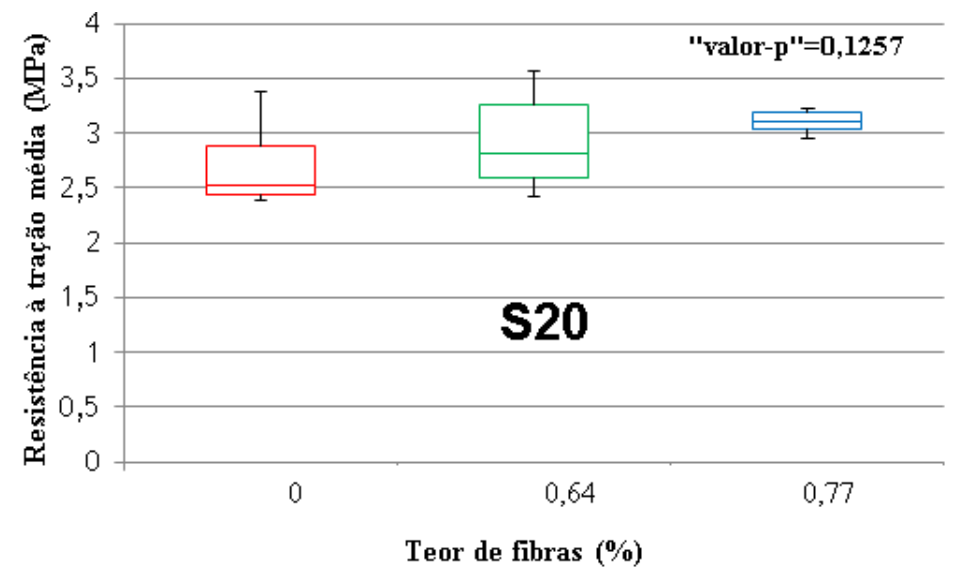

(a)

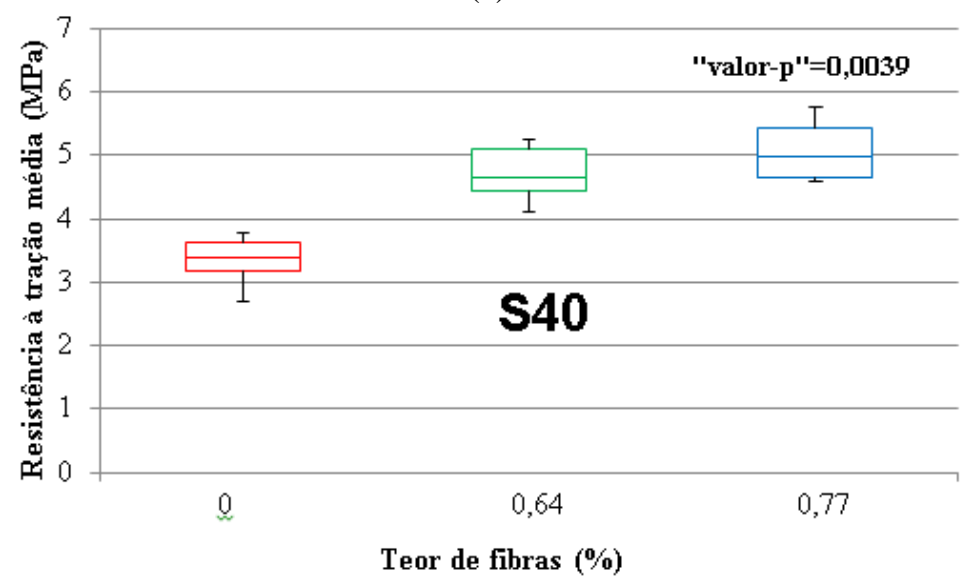

(b) 
Figura 10 - Curvas momento fletor $x$ deslocamento no meio do vão Série S20 (a) e Série S40 (b)

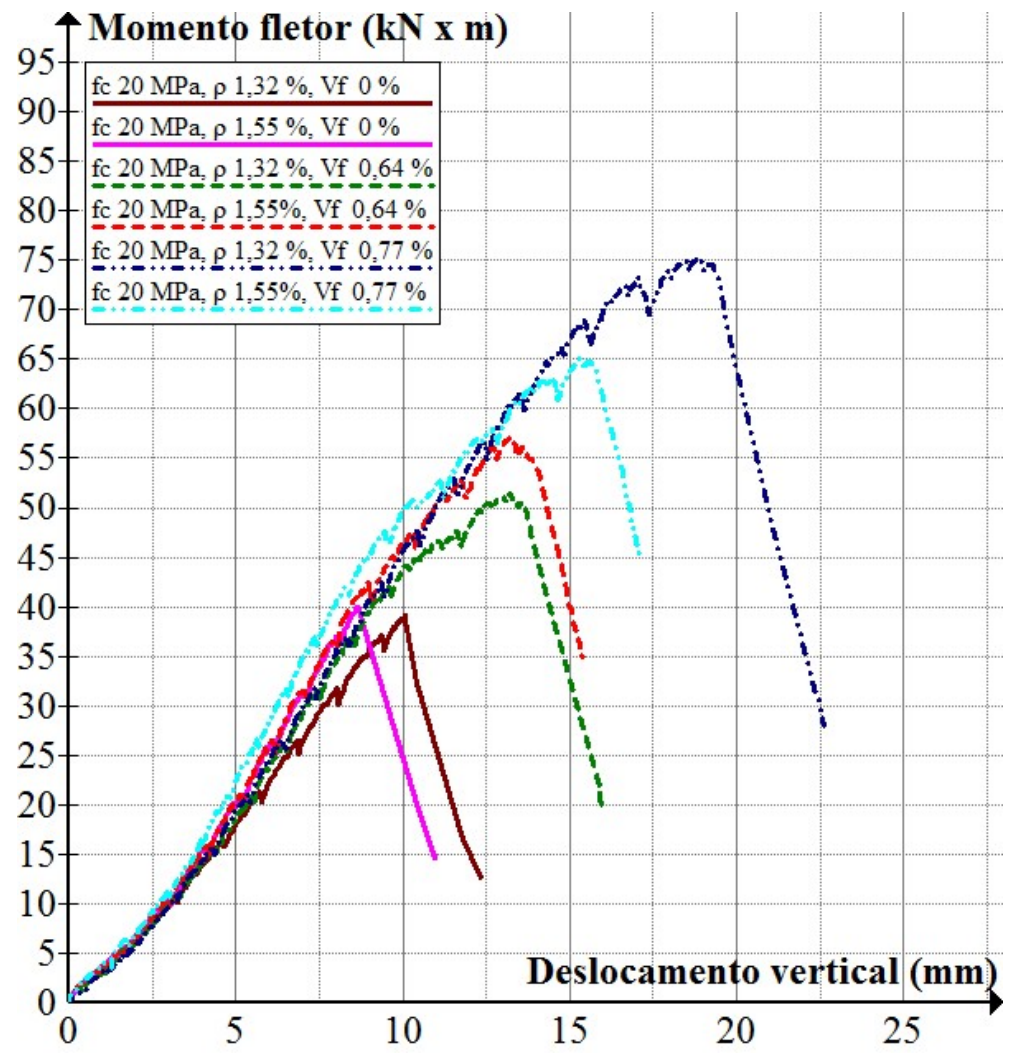

(a)

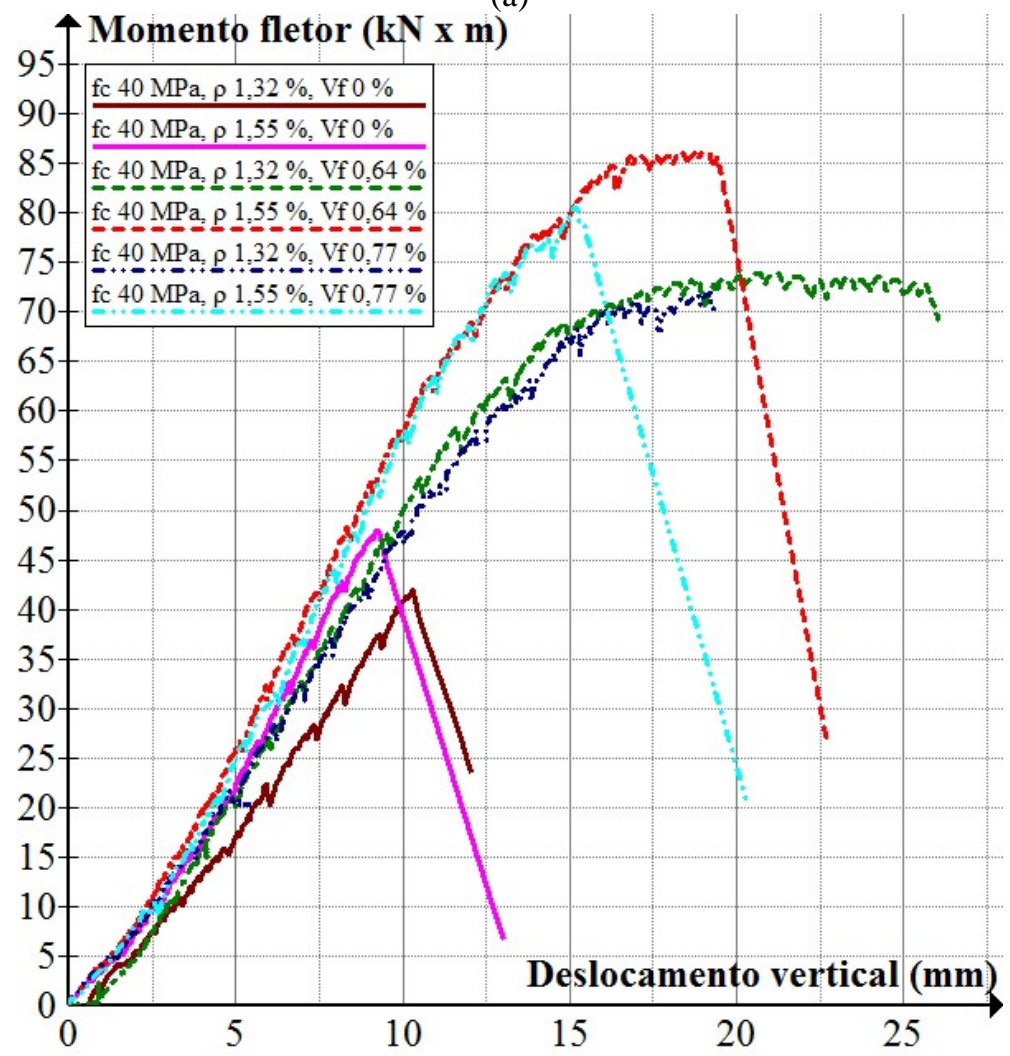

(b) 
Tabela 4 - Índice de ductilidade $\boldsymbol{\mu}_{\boldsymbol{d}}$

\begin{tabular}{c|c|c|c}
\hline Viga & $\begin{array}{c}\boldsymbol{\delta}_{\boldsymbol{u}} \\
(\mathbf{m m})\end{array}$ & $\begin{array}{c}\boldsymbol{\delta}_{\boldsymbol{y}} \\
(\mathbf{m m})\end{array}$ & $\boldsymbol{\mu}_{\boldsymbol{d}}$ \\
\hline S20A-0,64 & 14,28 & 12,17 & 1,17 \\
S20A-0,77 & 21,04 & 15,86 & 1,33 \\
S20B-0,64 & 15,39 & 11,52 & 1,34 \\
S20B-0,77 & 17,08 & 12,52 & 1,36 \\
S40A-0,64 & 26,00 & 13,80 & 1,88 \\
S40A-0,77 & 19,70 & 16,00 & 1,23 \\
S40B-0,64 & 19,75 & 15,40 & 1,28 \\
S40B-0,77 & 16,35 & 13,49 & 1,21 \\
\hline
\end{tabular}

Observa-se na Tabela 4 que na S20 o principal efeito de $\rho$ foi sobre a ductilidade das vigas. As vigas com $\rho$ de $1,32 \%$ apresentaram menores $\mu_{d}$ quando comparadas com as vigas com $\rho$ de $1,55 \%$ e mesmo teor de fibras e classe de resistência do concreto. O teor de fibras também apresentou influência na ductilidade das vigas da S20.

Na série S40 as vigas de CRFA com 0,77\% de fibras apresentaram menor ductilidade em termos do índice $\mu_{d}$ em comparação com as vigas com mesma classe de resistência de concreto e taxa de armadura longitudinal, e teor de fibras de 0,64\%. Conforme já observado por Sahoo e Sharma (2014), a queda da ductilidade das vigas com o aumento do teor de fibras pode ser atribuída à distribuição desigual das fibras na matriz de concreto quando utilizado um teor de fibras mais elevado.

\section{Deformações nas armaduras longitudinais de tração}

A evolução das deformações nas armaduras longitudinais de tração das vigas podem ser visualizadas na Figura 11. Nesses gráficos estão representadas as deformações dos extensômetros L0 colados na armadura na região do meio do vão.

Observa-se que não houve escoamento da armadura longitudinal de tração nas vigas sem fibras S20A-0, S20B-0, S40A-0 e S40B-0 conforme esperado, uma vez que não possuíam nenhum reforço ao cisalhamento.

Nas vigas de CRFA com concreto classe S20, a ocorrência do escoamento da armadura foi ditada pelo teor de fibras e pela taxa de armadura longitudinal. Enquanto nas vigas S20A-0,64 e S20B-0,64 e S20B-0,77 não foram observados escoamentos da armadura longitudinal, a viga com teor de fibras de $0,77 \%$ e taxa de armadura de 1,32 $\%$ (S20A-0,77) apresentou substancial escoamento da armadura longitudinal antes da ruptura. Esse escoamento demonstra o reforço à força cortante proporcionado pelas fibras que permitiram que fosse atingida a capacidade à flexão mesmo sem a presença de estribos.

Nas vigas de CRFA com concreto classe S40 houve escoamento da armadura longitudinal de tração nas vigas S40A-0.64, S40A-0.77 e S40B-0.64, o que demonstra o reforço ao cortante proporcionado pelas fibras de aço. Entre as vigas S40A-0.64 e S40A-0.77, a magnitude do escoamento da armadura foi ditada pelo teor de fibras.

\section{Modo de ruptura e padrão de fissuração}

O modo de ruptura de todas as vigas está listado na Tabela 2.

A presença de fibras de aço na matriz de concreto alterou o padrão de fissuração tanto na série S20 como na S40. Nas vigas sem fibras (S20A-0, S20B0, S40A-0 e S40B-0) a ruptura por cortante ocorreu sem nenhum aviso e o padrão de fissuração foi caracterizado pela formação de uma única fissura diagonal.

As vigas de CRFA que romperam por cortante (S20A-0,64, S20A-0,77, S20B-0,64, S20B-0,77 e S40B-0,77) apresentaram múltiplas fissuras diagonais e o alargamento de pelo menos uma delas antes da ruptura forneceu um aviso sobre o iminente colapso. Segundo Dinh, Parra-Montesinos e Wight (2010), credita-se a ruptura por cisalhamento nas vigas de CRFA à deterioração da aderência ao longo da armadura longitudinal próxima ao apoio. Essa deterioração é atribuída aos vazios que se desenvolvem durante a moldagem do concreto, aglomeração de fibras ao longo da armadura longitudinal ou uma combinação de ambos. 
Figura 11 - Evolução das deformações nas armaduras extensômetro L0 Série S20A (a), Série S20B (b), S40 A(c) e S40 (d)

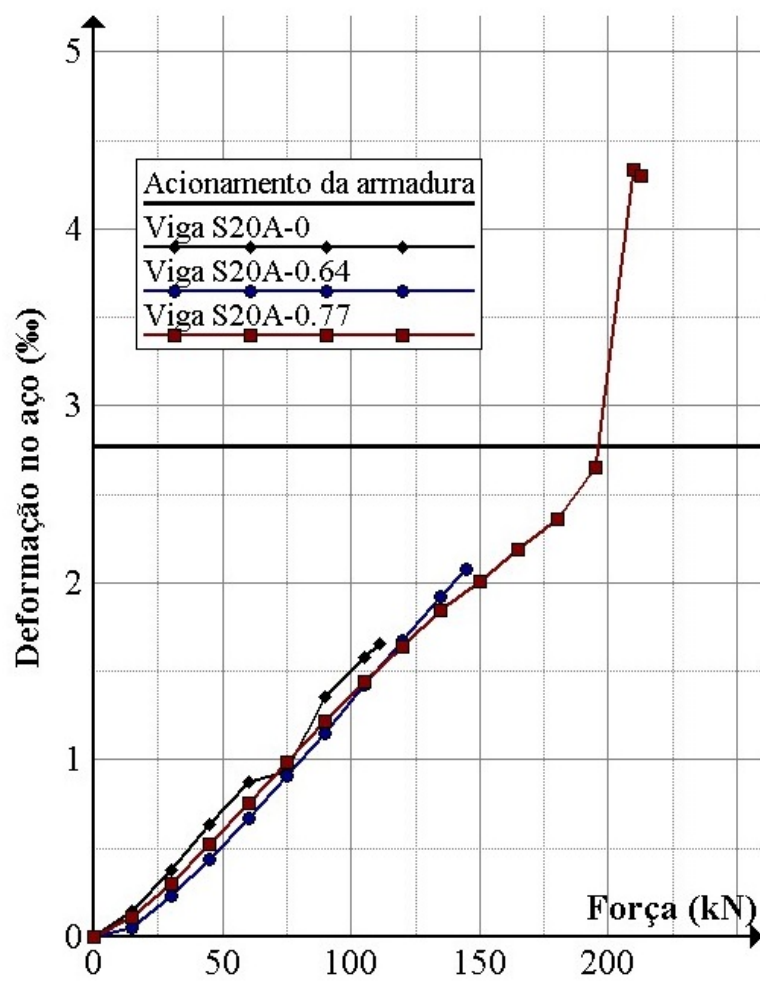

(a)

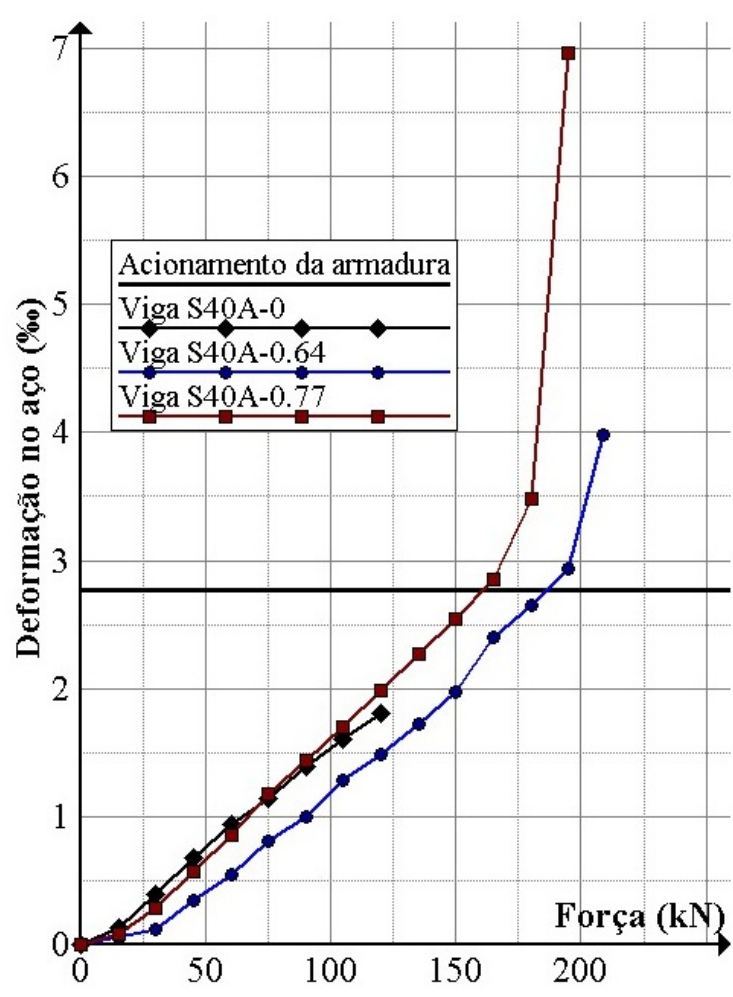

(c)

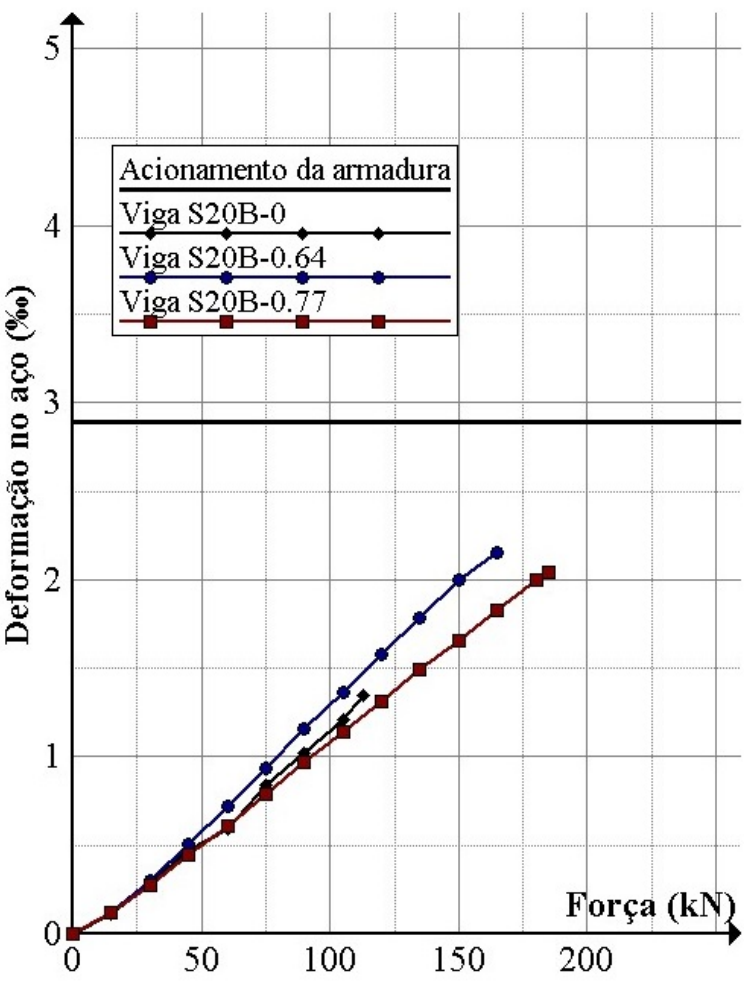

(b)

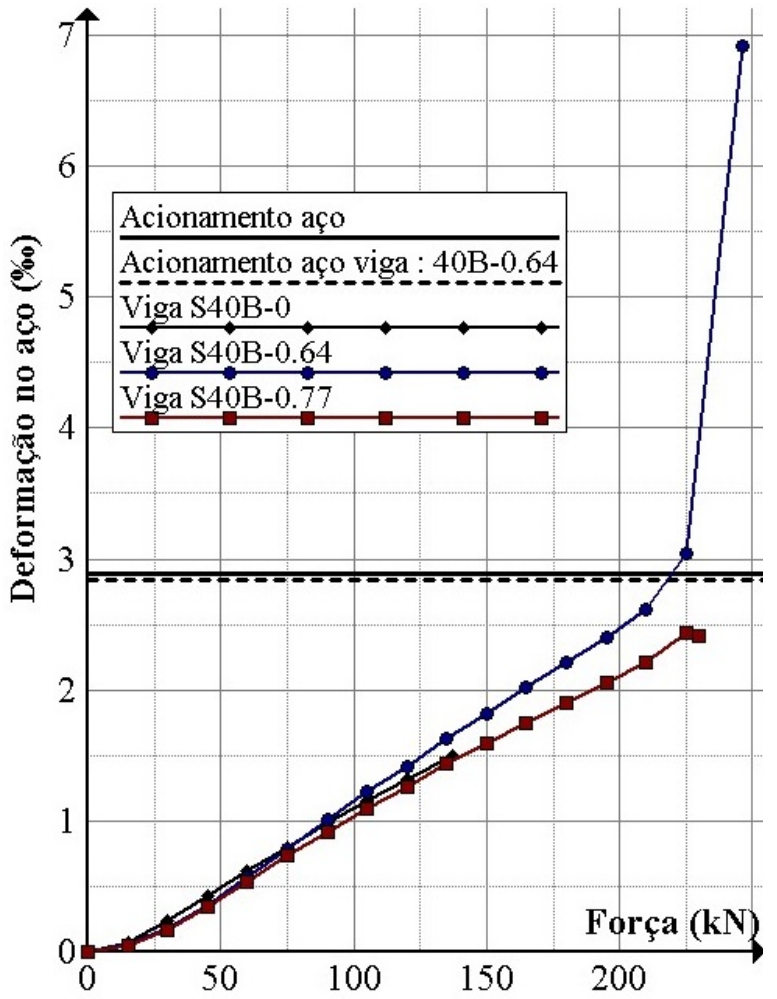

(d) 
As vigas que romperam por uma combinação cortante-flexão (S40A-0,64, S40A-0,77 e S40B0,77) desenvolveram um número significativo de fissuras diagonais e de flexão e várias dessas fissuras interagiram para causar a ruptura. Conforme pode ser visualizado na Figura 12, com o aumento do teor de fibras houve alteração no padrão de fissuração com a formação de pelo menos duas fissuras diagonais, um maior número de fissuras de flexão com menor espaçamento entre elas.

\section{Resistência ao cisalhamento última}

As resistências ao cisalhamento última $\left(v_{u}\right)$ obtidas para as vigas estão descritas na Tabela 2 em termos de resistência ao cisalhamento média na ruptura, calculada utilizando a Equação 3.

$v_{u}=\frac{v_{u}}{d \times b_{w}}$

O efeito do teor de fibras na resistência ao cisalhamento esta ilustrado na Figura 13. Neste gráfico é possível observar aumentos na resistência ao cisalhamento com a adição de fibras de aço.

Na série S20 (resistência à compressão próxima de $20 \mathrm{MPa}$ ) houve um acréscimo da $v_{u} / \sqrt{f_{c}}$ quando o teor de fibras foi aumentado de $0,64 \%$ para $0,77 \%$. Esse aumento foi mais significativo para taxa de armadura de 1,32\% (série A), em que o aumento do teor de fibras de $0,64 \%$ para $0,77 \%$ foi acompanhado por uma elevação da $v_{u} / \sqrt{f_{c}}$ de $41,40 \%$.

Na série S40 (resistência à compressão próxima de $40 \mathrm{MPa}$ ) o aumento do teor de fibras de $0,64 \%$ para $0,77 \%$ foi acompanhado por uma redução da $v_{u} / \sqrt{f_{c}}$ de $11,25 \%$ na série S40A e 3,61\% na série S40B.

Autores como Dinh, Parra-Montesinos e Wight (2010) e Yakoub (2011) também observaram queda na eficiência do reforço das fibras com o aumento do teor de fibras. No entanto, esse efeito ocorreu quando utilizado um teor de fibras elevado, particularmente para além de $1 \%$.

Analisando a resistência ao cisalhamento normalizada pela resistência à compressão $\left(v_{u} / \sqrt{f_{c}}\right)$, as vigas com maiores valores de $v_{u} / \sqrt{f_{c}}$, S20A-0,77 e S40B-0,64 apresentaram um nível de tensão de cisalhamento normalizada mais de 1,5 vez superior às vigas sem fibras e com mesma taxa de armadura longitudinal. O menor valor de $v_{u} / \sqrt{f_{c}}$ nas vigas de CRFA foi observado na S20B-0,64, entretanto o seu valor foi $47 \%$ superior quando comparada à viga S20B-0.

\section{Figura 12 - Alteração do padrão de fissuração com o aumento do teor de fibras: viga S40-0 (a), Viga S40A-0.64 (b) e viga S40A-0.77 (c)}

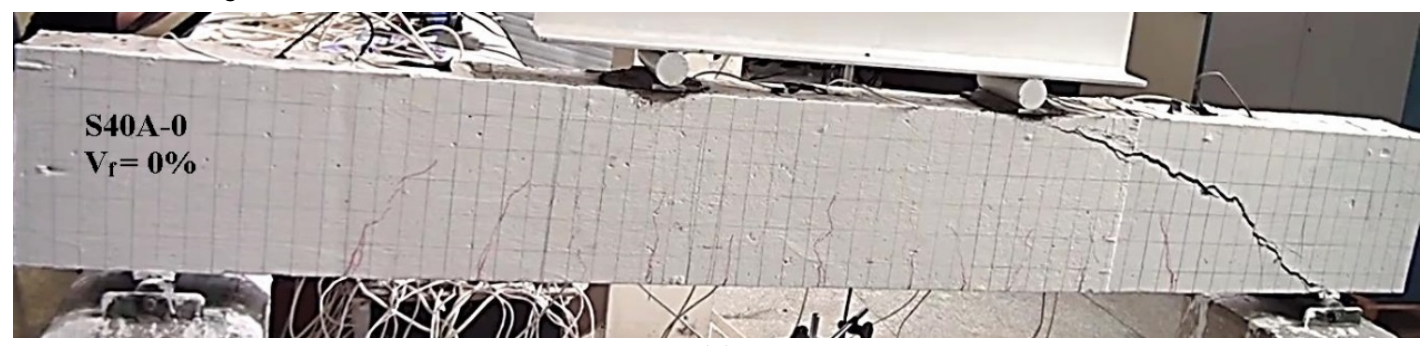

(a)

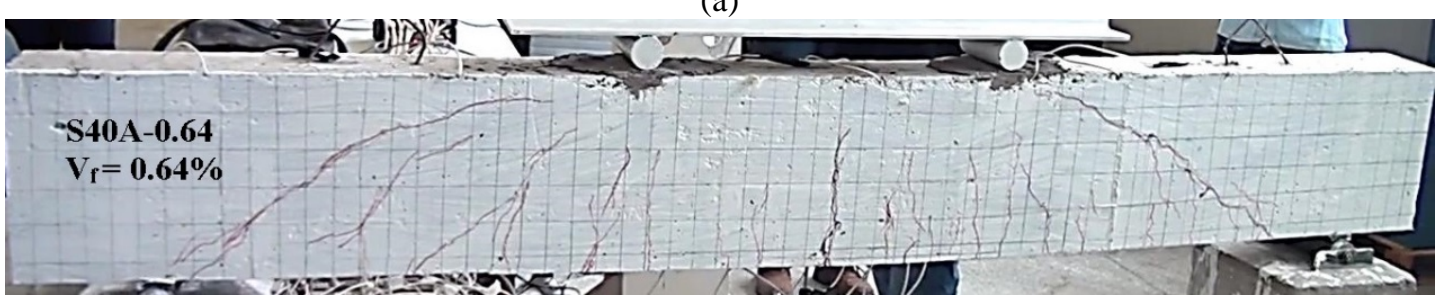

(b)

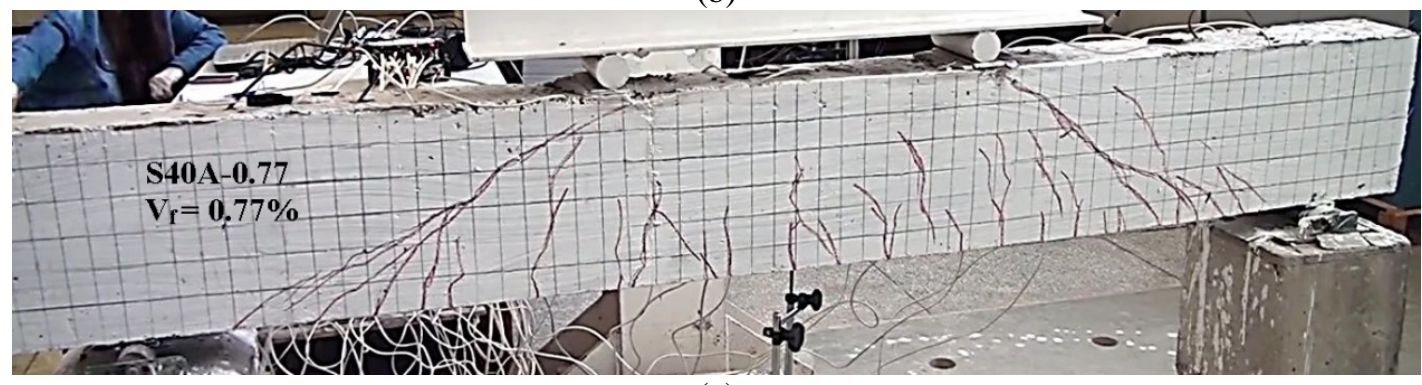

(c) 
Figura 13 - Efeito do teor de fibras na resistência ao cisalhamento última

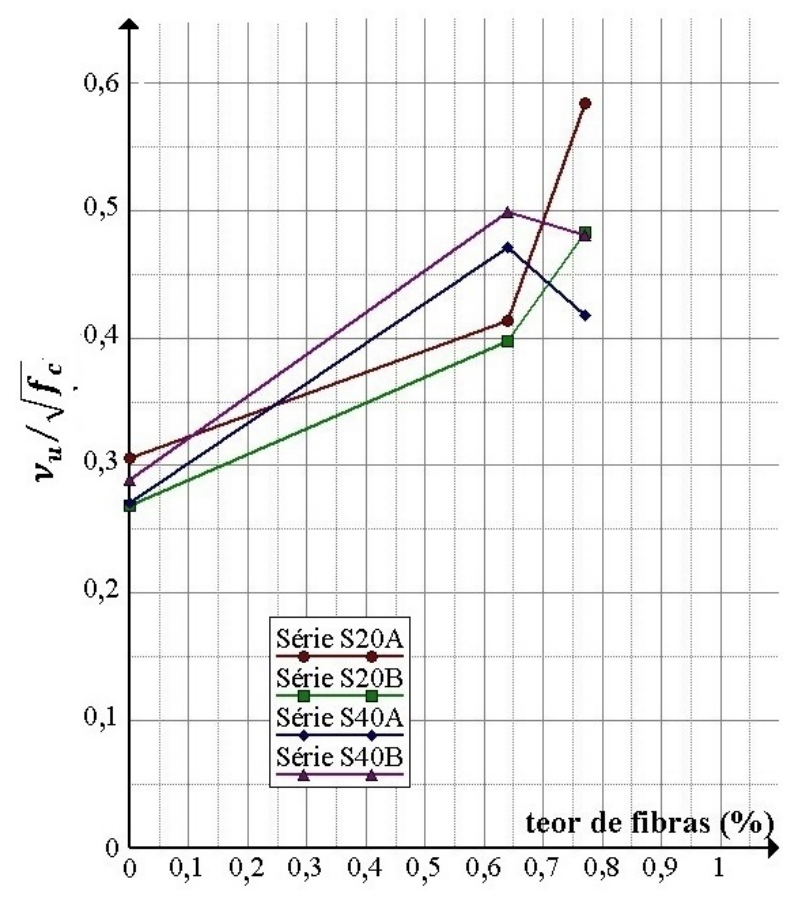

O efeito da resistência à compressão na resistência ao cisalhamento última pode ser observado analisando as vigas com mesma $\rho$ e mesmo teor de fibras. Para as vigas S20A-0,64 e S40A-0,64, o aumento de $60 \%$ na resistência à compressão foi acompanhado de um aumento de $44 \%$ na resistência ao cisalhamento última. Já nas vigas S20B-0,77 e S40B-0,77, o aumento de 56\% na resistência à compressão foi acompanhado de um aumento de $24,3 \%$ na $v_{\mathrm{u}}$. Khuntia, Stojadinovic e Goel (1999) também observaram aumentos na resistência ao cisalhamento com o aumento da resistência à compressão, os autores atribuem esse efeito devido ao aumento da aderência fibra matriz com a elevação da $f_{c}$, uma vez que a influência da resistência à compressão do concreto sobre a resistência ao cisalhamento é insignificante e pode ser ignorada na análise de carga de ruptura diagonal ou tensão de cisalhamento admissível em vigas de concreto armado (KANI, 1966; ANGELAKOS 1999).

\section{Conclusões}

Neste trabalho foi investigado o comportamento de vigas de CRFA submetidas à flexão em quatro pontos. Um total de doze vigas foi ensaiado para investigar a influência do teor de fibras, da taxa de armadura longitudinal de tração e resistência do concreto à compressão no modo de ruptura e resistência da viga ao cisalhamento. Também foi avaliada a influência da adição de fibras na resistência à compressão e resistência à tração por compressão diametral de corpos de prova cilíndricos de concreto. Os objetivos do estudo foram alcançados e foi possível retirar as seguintes conclusões:

(a) a adição de fibras de aço ao concreto tem efeito significativo na resistência à tração por compressão diametral, ocorrendo um aumento da resistência à tração com o aumento do $\mathrm{V}_{\mathrm{f}}$. Ao contrário, o efeito das fibras sobre a resistência à compressão foi pouco significativo;

(b) com o aumento do teor de fibras ocorreu elevação momento último e o deslocamento último para concretos classe 20 e 40;

(c) a presença de fibras de aço na matriz de concreto alterou o padrão de fissuração tanto na série S20 como na S40, com a formação de pelo menos duas fissuras diagonais, um maior número de fissuras de flexão com menor espaçamento entre elas. Esse padrão de fissuração foi mais favorável para a segurança, uma vez que proporcionou uma ruptura mais avisada;

(d) a adição de fibras de aço com gancho na extremidade na matriz de concreto aumentou a resistência ao cisalhamento de vigas submetidas à flexão do ponto de vista de $v_{u} / \sqrt{f_{c}}$; e

(e) o principal efeito da $\rho$ foi sobre a ductilidade das vigas. As vigas com $\rho$ de 1,32\% apresentaram maiores deformações da armadura longitudinal de tração que as vigas com $\rho$ de 1,55\%. Essa 
deformação na armadura longitudinal foi primeiramente ditada pelo teor de fibras.

\section{Referências}

AMERICAN CONCRETE INSTITUTE. ACI 318: Building code requirements for structural concrete. Michigan, 2014.

AMERICAN CONCRETE INSTITUTE. ACI 544.4R: Design considerations for steel fiber reinforced concrete. Michigan, 1988. Reapproved 2009.

ANGELAKOS, D. The Influence of Concrete Strength and Longitudinal Reinforcement Ratio on the Shear Strength of Large-Size Reinforced Concrete Beams With, and Without, Transverse Reinforcement. Toronto, 1999. 182 f. Master Thesis, Department of Civil Engineering, University of Toronto, Toronto, 1999.

AOUDE, H. et al. Response of Steel FiberReinforced Concrete Beams with and without Stirrups. ACI Structural Journal, Farmington Hills, v. 109, n. 3, may/jun. 2012.

ASSOCIAÇÃO BRASILEIRA DE NORMAS TÉCNICAS. NBR 5739: concreto: ensaio de compressão de corpos-de-prova cilíndricos. Rio de Janeiro, 2007.

\section{ASSOCIAÇÃO BRASILEIRA DE NORMAS} TÉCNICAS. NBR 6118: projeto de estruturas de concreto: procedimento. Rio de Janeiro, 2014.

ASSOCIAÇÃO BRASILEIRA DE NORMAS TÉCNICAS. NBR 7222: concreto e argamassa: determinação da resistência à tração por compressão diametral de corpos de prova cilíndricos. Rio de Janeiro, 2011.

ASSOCIAÇÃO BRASILEIRA DE NORMAS Técnicas. NBR NM 67: concreto: determinação da consistência pelo abatimento do tronco de cone. Rio de Janeiro, 1998.

BARROS, J. A. O. Estado-da-Arte dos Betões Reforçados Com Fibras. Engenharia Civil Um, Guimarães, v. 3, p. 29-47, 1996.

BENTUR, A.; MINDESS, S. Fibre Reinforced Cementitious Composites. $2^{\text {nd }}$ ed. London: Elsevier, 2007.

DINH, H. H.; PARRA-MONTESINOS, G. J.; WIGHT, J. Shear Behavior of Steel FiberReinforced Concrete Beams Without Stirrup Reinforcement. ACI Structural Journal, Farmington Hills, v. 107, n. 5, sep./oct. 2010.
FÉDÉRATION INTERNATIONALE DU

BÉTON. Model Code 2010: first complete draft. v. 2. Switzerland, 2010.

FIGUEIREDO, A. D. Concreto Reforçado Com Fibras de Aço. São Paulo, 2011. 247 f. Tese (Livre Docência) - Escola Politécnica, Universidade de São Paulo, São Paulo, 2011.

HANNANT, D. J. Fibre Cements and Fibre Concretes. Chichester: John Wiley, 1978.

KANG, T. H. K. et al. Shear-Flexure Coupling Behavior of Steel Fiber-Reinforced Concrete Beams. ACI Structural Journal, Farmington Hills, v. 109, n. 4, p. 435-444, jul./aug. 2012.

KANI, G. N. J. Basic Facts Concerning Shear Failure. ACI Journal, v. 63, n. 06, p. 675-692, jun. 1966.

KHUNTIA, M.; STOJADINOVIC, B.; GOEL, S. Shear Strength of Normal and High-Strength Fiber Reinforced Concrete Beams without Stirrups. ACI Structural Journal, v. 96, n. 2, p. 282-289, 1999.

KWAK, Y. K. et al. Shear Strength of Steel FiberReinforced Concrete Beams Without Stirrups.

ACI Structural Journal, Farmington Hills, 530538, jul./aug. 2002.

MEHTA, P. K.; MONTEIRO, P. J. M. Concreto: microestrutura, propriedades e materiais. 2. ed. São Paulo: IBRACON, 2014.

OLIVEIRA JUNIOR, L. A. Ligação Viga-Pilar em Elementos Pré-Moldados de Concreto Solidarizados Por Concreto Reforçado Com Fibras de Aço: análise estática e dinâmica. São Carlos, 2012. 233f. Tese (Doutorado em Engenharia de Estruturas) - Escola de Engenharia, Universidade de São Paulo, São Carlos, 2012.

SAHOO, D. R.; SHARMA, A. Effect of Steel Fiber Content on Behavior of Concrete Beams With and Without Stirrups. ACI Structural Journal, v. 111, n. 5, p. 1157-1167, sep./oct. 2014.

SINGH, B; JAIN, K. Apraisal of Steel Fibers as Minimum Shear Reinforcement in Concrete Beams. ACI Structural Journal, Farmington Hills, v. 111, n. 5, p. 1191-1203, sep./oct. 2014.

SLATER, E.; MONI, M.; ALAM, M. S. Predicting the Shear Strength of Steel Fiber Reinforced Concrete Beams. Construction and Building Materials, Oxford, v. 26, p. 423-436, jun. 2012.

YAKOUB, H. E. Shear Stress Prediction: steel fiber-reinforced concrete beams without stirrups. ACI Structural Journal, Farmington Hills, v. 103, n. 3, p. 304-444, may/jun. 2011. 


\section{Agradecimentos}

Os autores agradecem a ajuda financeira da CAPES, a doação das fibras de aço pela empresa
Belgo Bekaert e a doação do aditivo superplastificante pela empresa Basf.

Paula de Carvalho Palma Vitor

Faculdade de Engenharia Civil | Universidade Federal de Uberlândia | Av. J oão Naves de Ávila, 2121, Santa Mônica | Uberlândia - MG Brasil | CEP 38400-902 | Tel.: (34) 3239-4170 | E-mail: ppalmavitor@gmail.com

Antônio Carlos dos Santos

Faculdade de Engenharia Civil | Universidade Federal de Uberlândia | E-mail: acds@ufu.br

\section{Leandro Mouta Trautwein}

Faculdade de Engenharia Civil, Arquitetura e Urbanismo | Universidade Estadual de Campinas | Av.a Albert Einstein, 951, Barão Geraldo | Campinas - SP - Brasil | CEP 13083-852 | Tel.: (19) 3521-2338 | E-mail: leandromt@gmail.com

\section{Revista Ambiente Construído}

Associação Nacional de Tecnologia do Ambiente Construído

Av. Osvaldo Aranha, 99 - 3o andar, Centro

Porto Alegre - RS - Brasil

CEP $90035-190$

Telefone: +55 (51) 3308-4084

Fax: +55 (51) 3308-4054

www. seer. ufrgs. br/ ambienteconstruido

E-mail: ambienteconstruido@ufrgs.br 


\section{Errata}

No artigo "Resistência ao cisalhamento em vigas de concreto armado sem armadura transversal reforçadas com fibras de aço", com número de DOI: < http://dx.doi.org/10.1590/s167886212018000300280>, publicado no periódico Ambiente Construído, 18(3):255-271.

Na página 255:

Onde se lia (filiação e autoria):

"Leandro Moura Trautwein"

Leia-se:

"Leandro Mouta Trautwein"

Onde se lia:

"Campinas - SP - Beasil"

Leia-se:

"Campinas - SP - Brasil"

Na página 270:

"Leandro Moura Trautwein"

Leia-se:

"Leandro Mouta Trautwein"

Onde se lia:

"Campinas - SP - Beasil"

Leia-se:

"Campinas - SP - Brasil" 